Jpn. J. Genet. (1983) 58, pp. 545-553

\title{
Interspecific transfer of only part of genome by fusion between non-irradiated protoplasts of Nicotiana glauca and $\mathrm{X}$-ray irradiated protoplasts of $N$. langsdorffii
}

\author{
By Kazuya ItOH and Yuzo FutsuHARA* \\ Kameyama Breeding Station, Oji Institute for Forest Tree Improvement, \\ Oji Paper Co. Ltd., Nobonocho Kameyama 519-02 \\ and \\ *Faculty of Agriculture, Nagoya University, Nagoya 464
}

(Received July 15, 1983)

\begin{abstract}
To transfer only part of genome, X-ray irradiated suspension cell protoplasts of $N$. langsdorffi $i$ were fused with suspension cell protoplasts of $N$. glauca by polyethylene glycol. Somatic hybrid calli were selected by the growth in the hormone-free medium. Some of somatic hybrid calli from fusion with irradiated protoplasts indicated the loss of small subunit polypeptide of fraction 1 protein which was coded by $N$. langsdorffi nuclear DNA. Cytological analysis provided an information on significant decrease of chromosomes in somatic hybrid calli from fusion with irradiated protoplasts, compared with the somatic hybrid calli from fusion with non-irradiated protoplasts. In addition, isozyme analysis revealed that somatic hybrid calli from fusion with irradiated protoplasts lost particular bands of $N$. langsdorffi. These results demonstrate the tranfer of only part of genome from $N$. langsdorffi $i$ to $N$. glauca by fusion with X-ray irradiated protoplasts.
\end{abstract}

\section{INTRODUCTION}

Somatic hybridization using protoplast fusion offers a great potential to somatic cell genetics, because genetic exchange has a good chance of realization between species which cannot be crossed using conventional method. However, somatic hybridization results in parasexual integration of complete parental genomes. Although somatic hybrid plants between distantly related plants and between sexually incompatible plants have been reported (Melchers et al. 1978; Gleba and Hoffmann 1979; Krumbiegel and Schieder 1981; Shepard et al. 1983), these plants have undesirable portions of the alien genome. Accordingly, we need suitable methods to eliminate undesirable genes.

In fusion with distantly related species, somatic incompatibility has been reported, such as the elimination of chromosomes at the times of hybrid cell division (Kao 1977; Binding and Nehls 1978) and of plant regeneration (Hoffmann and Adachi 1981). In extreme case, alien gene expression has been observed even after alien visible chromosomes were completely eliminated 
(Power et al. 1975; Dudits et al. 1979). These phenomena are not always observed in many other protoplast fusion. On the other hand, accelerated elimination of one of the parental chromosome sets from the hybrid cell has been observed in fusion between non-irradiated and irradiated protoplasts. This method was successfully used in the transfers of nuclear markers (Dudits et al. 1980; Gupta et al. 1982) and of cytoplasmic male sterility (Zelcer et al. 1978; Menczel et al. 1982).

In the present paper, to investigate the possibility for the transfer of only part of genome in interspecific fusion, X-ray irradiated protoplasts of $N$. langsdorffii were fused with non-irradiated protoplasts of $N$. glauca. As genetic tumor formation may depend upon the presence of a specific $N$. langsdorffi chromosomes in an otherwise N. glauca background (Ahuja 1968), protoplasts of $N$. langsdorffi $i$ were irradiated. The somatic hybrid calli indicated the expression of genetic tumor and the elimination of chromosomes of $N$. langsdorffi.

\section{MATERIALS AND METHODS}

Plant materials and culture conditions

Suspension cultures were originated from the calli of the stem of $N$. glauca and $N$. langsdorffii. These were maintained on the medium containing Murashige and Skoog (1962, MS) inorganic and organic components plus $1 \mathrm{mg} / l 2$, 4-dichlorophenoxyacetic acid (2, 4-D), $0.1 \mathrm{mg} / l$ 6-benzyladenine (BA), and $30 \mathrm{~g} / l$ sucrose ( $\mathrm{pH}$ 5.6). Suspension cultured cells were subcultured at 14 day intervals.

\section{Protoplast isolation, inactivation and fusion}

Protoplasts from suspension cultures of both species were prepared by adding the enzyme solution ( $1 \%$ Cellulase Onozuka R-10, $0.2 \%$ Macerozyme R-10, $0.05 \%$ Pectolyase Y-23 in 13\% mannitol, pH 5.6). Suspension cells of both species were incubated at $30^{\circ} \mathrm{C}$ for 4 hours. After 3.5 hours of incubation suspension cells of $N$. langsdorffii were irradiated with X-rays of $6 \mathrm{KR}$ $(190 \mathrm{KV}, 20 \mathrm{~mA}, 400 \mathrm{R} / \mathrm{min}$.) in enzyme solution. Protoplast fusion was induced by the method of Uchimiya (1982). Fused protoplasts were cultured on a circular cover slip (22 $\mathrm{mm}$ in diameter) in a petri dish $(6 \mathrm{~cm}$ in diameter) at $28^{\circ} \mathrm{C}$ under permanent illumination (about $1000 \mathrm{lux}$ ). Protoplast culture medium contained MS inorganic and organic components plus $3 \mathrm{mg} / \mathrm{l} 2,4-\mathrm{D}$, $0.5 \mathrm{mg} / l \mathrm{BA}, 30 \mathrm{~g} / l$ sucrose and $0.4 \mathrm{M}$ glucose $(\mathrm{pH} 5.6)$.

\section{Selection of somatic hybrid colony}

After two or four weeks cultured protoplasts were washed twice with hormone-free protoplast culture medium and plated the same medium $(0.6 \%$ 
agar) to select somatic hybrid colonies. Formed somatic hybrid colonies were then replaced on the medium of MS inorganic and organic components plus $30 \mathrm{~g} / l$ sucrose and $0.8 \%$ agar $(\mathrm{pH}$ 5.6). Subsequently, somatic hybrid calli were subcultured on the agar medium or in the liquid medium.

\section{Analysis of somatic hybrid calli}

Fraction 1 protein, an useful genetic marker for nuclear and chloroplast genomes, were analyzed with the method of Hirai (1982) without carboxymethylation, using materials of somatic hybrid calli which were subcultured about a half year after fusion. In chromosome staining, the method of Kao (1975) was used with modifications. Somatic hybrid calli were incubated with the enzyme solution $(0.5 \%$ Cellulase Onozuka R-10, $0.01 \%$ Pectolyase Y-23 in $0.1 \mathrm{M}$ sodium acetate buffer, $\mathrm{pH} 4.5$ ) for one hour and stained with $10 \%$ carbol fuchsin for one hour. Polyacrylamide gel electrophoresis of peroxidase in the presence of sodium dodecyl sulfate (SDS) was performed according to the method of Laemmli (1970). Crude extracts from calli or leaves were prepared by homogenizing them (1 $\mathrm{g}$ fresh weight) in $1 \mathrm{ml}$ of $0.03 \mathrm{M}$ Tris ( $\mathrm{pH}$ 8.0) containing $6 \mathrm{M}$ urea, $0.01 \% \beta$-mercaptoethanol and $0.2 \% \mathrm{SDS}$. The separation gel contained either $7.5 \%$ or $15 \%$ acrylamide, $\mathrm{N}, \mathrm{N}^{\prime}$-methylenebisacrylamide (BIS), at 0.2 to $0.4 \%, 0.42 \mathrm{M}$ Tris, $\mathrm{pH} 8.8,0.05 \% \mathrm{~N}, \mathrm{~N}, \mathrm{~N}^{\prime}, \mathrm{N}^{\prime}$-tetramethylethylenediamine (TEMED), $0.08 \%$ ammonium persulfate, and $0.1 \%$ SDS. The stacking gel contained $4.7 \%$ acrylamide, $0.13 \%$ BIS, $0.4 \mathrm{M}$ Tris, pH 6.8 , $0.04 \%$ TEMED, $0.03 \%$ riboflavin, and $0.1 \%$ SDS. The electrode buffer contained $0.19 \mathrm{M}$ glycine, $0.025 \mathrm{M}$ Tris and $0.1 \%$ SDS. Electrophoresis was conducted at room temperature with constant voltage of $50 \mathrm{~V}$ until bromphenol blue reached at the bottom of the slab gels. Renaturation of enzymes after SDS polyacrylamide gel electrophoresis was conducted by the method of Blank et al. (1982). The gel was stained using $100 \mathrm{mg}$ of benzidine acetate in $100 \mathrm{ml}$ of $0.01 \mathrm{M}$ Tris-acetate buffer ( $\mathrm{pH} 4.1$ ) plus $0.3 \mathrm{ml}$ of hydrogen peroxide solution $(30 \%)$. Esterase isozymes were analyzed by polyacrylamide gel $(8 \%)$ electrophoresis (Moore and Collins 1982). Staining was carried out with the method of Kahler and Allard (1970).

\section{RESULTS}

Protoplasts of N. glauca and fusion-treated protoplasts initiated to divide at the second day of culture, however, X-ray irradiated protoplasts of $N$. langsdorffii could not divide. After 2 or 4 weeks, colonies were transferred on the selective medium. On this medium, colonies from fusion either between nonirradiated protoplasts or between non-irradiated and irradiated protoplasts could divide continuously to form fast growing green calli which had occasionally shoot-like structure on the surface. But these structures were not 


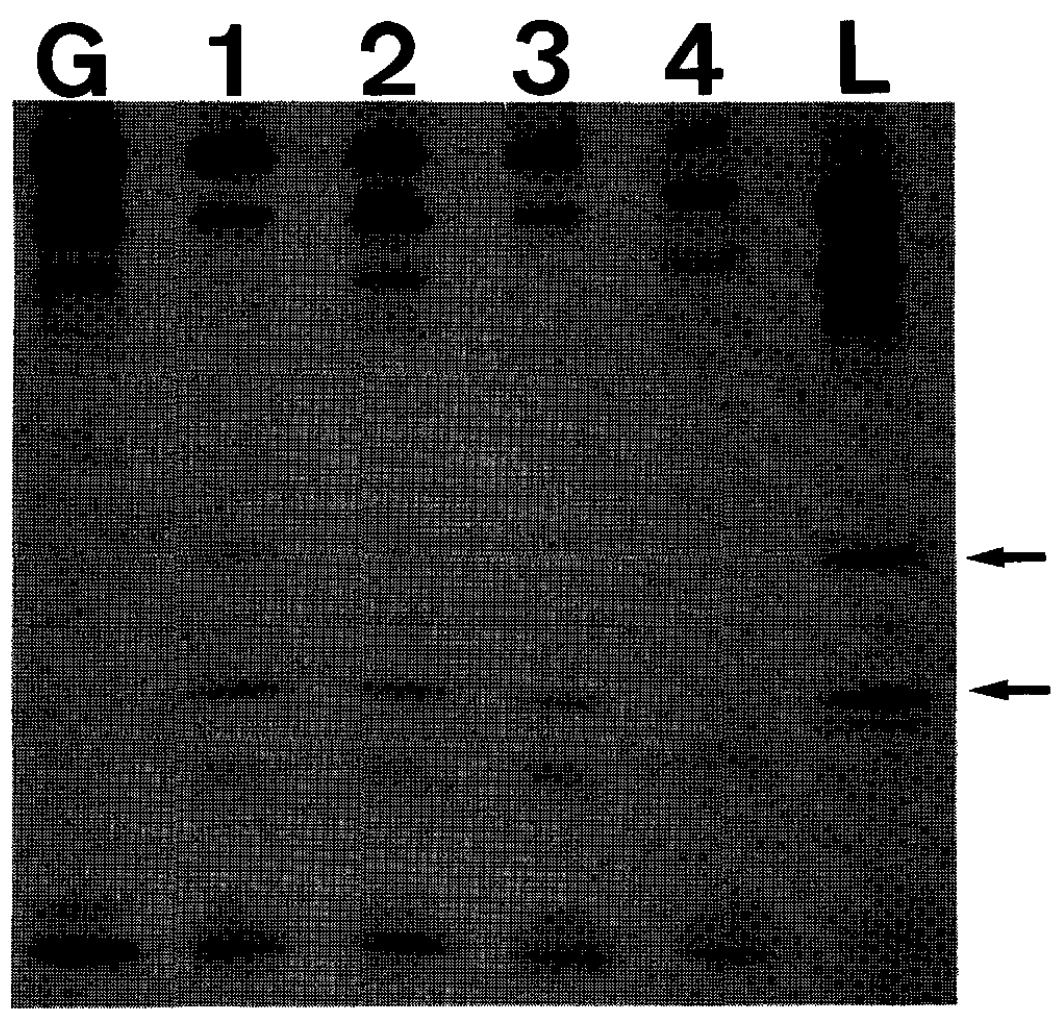

Fig. 1. Isoelectrofocusing analysis of fraction 1 protein from $N$. glauca (G), N. langs$\operatorname{dorffii}(\mathrm{L})$ and somatic hybrid calli originated from fusion with $\mathrm{X}$-ray irradiated protoplasts of $N$. langsdorffii $(\mathrm{G}+\mathrm{L}-\mathrm{X}): \mathrm{G}+\mathrm{L}-\mathrm{X}$ III (1), IV (2), V (3) and VII (4). Arrows indicate the small subunit polypeptide bands of $N$. langsdorffi

able to grow on the selective medium.

To determine the hybrid nature of formed calli, isoelectrofocusing of fraction 1 protein was carried. As shown in Fig. 1, the protein of N. glauca (G) had a small subunit composed of a single polypeptide whose isoelectric point was different from that of the two polypeptides of $N$. langsdorffii $(\mathrm{L})$ protein. Three polypeptide bands were seen in somatic hybrid calli originated from fusion between non-irradiated protoplasts of $N$. langsdorffi and $N$. glauca. The presence of the combined $G$ and $L$ small subunits of the fraction 1 protein provides evidence for both $\mathrm{G}$ and $\mathrm{L}$ nuclear contributions. On the other hand, the same small subunit polypeptide band pattern was seen in a somatic hybrid callus $(\mathrm{G}+\mathrm{L}-\mathrm{X} \mathrm{III})$. On the contrary, one or two small subunit polypeptides of $N$. langsdorffi protein were lost in somatic hybrid calli originated from fusion with irradiated protoplasts of $N$. langsdorffi (G+L-X VII, V, IV). This suggests the elimination of genetic material coded for small subunit polypeptides of $N$. langsdorffi . 
Interspecific transfer of only part of genome by fusion

Table 1. Comparison of chromosome numbers between parental cells and fused cells

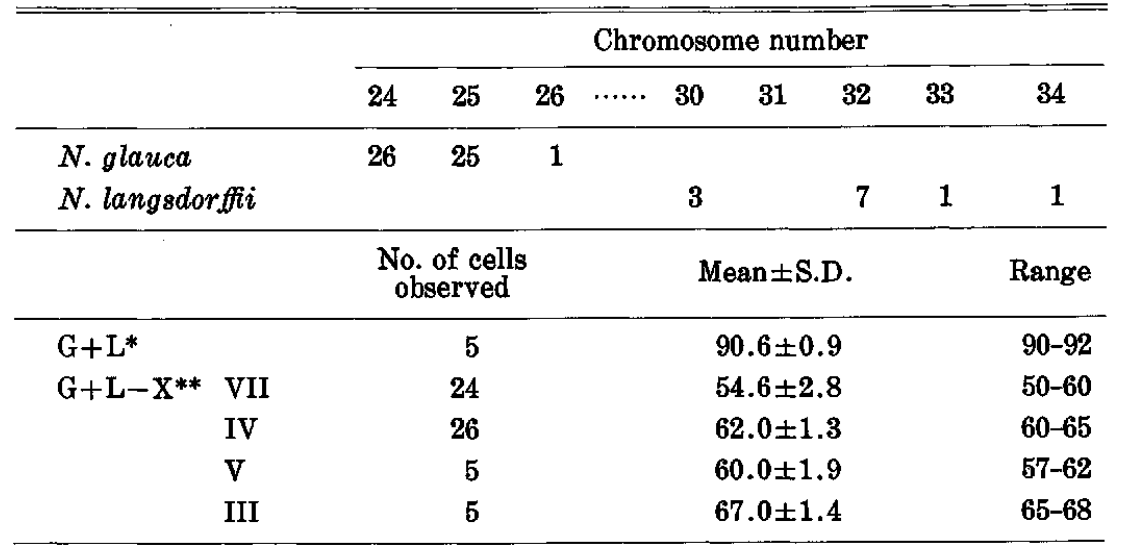

* Somatic hybrid calli originated from fusion with non-irradiated protoplasts of $N$. langsdorffii.

** Somatic hybrid calli originated from fusion with X-ray treated protoplasts of N. langsdorffii.

Diploid chromosome numbers of $N$. glauca and $N$. langsdorffi are 24 and 18 respectively. From cytological analysis in both species, the variability of chromosome numbers was found, particularly in $N$. langsdorffi (Table 1). Moreover, cells of the other cell strain of $N$. langsdorffi $i$ which was not utilized for fusion had about 44 chromosomes. Thus, cultured cells of $N$. langsdorffii were more variable in our culture condition, while cultured cells of $N$. glauca had slightly modified number of chromosomes (Fig. 2). Somatic hybrid cells from fusion with non-irradiated protoplasts of $N$. langsdorffii $(\mathrm{G}+\mathrm{L})$ had about 90 chromosomes which were more than the sum of chromosome numbers of $N$. glauca and N. langsdorffi cultured cell protoplasts. On the contrary, in somatic hybrid cells from fusion with $\mathrm{X}$-ray irradiated protoplasts $(\mathrm{G}+\mathrm{L}-\mathrm{X})$, cells indicated decrease number of chromosomes, compared with $\mathrm{G}+\mathrm{L}$ cells. $\mathrm{G}+\mathrm{L}-\mathrm{X}$ VII, which have lost all of small subunit polypeptides of $N$. langsdorffii, showed conspicuous decrease of chromosome number (Table 1). Moreover, these cells had more or less chromosome fragments (Fig. 2).

To examine the extent of the elimination of $N$. langsdorffi genome, isozyme analysis was performed. Fig. 3 indicates the result of SDS gel electrophoresis of peroxidase. Though tissue specific patterns were seen, particular differences were observed in the bands of low molecular weight (indicated with a arrow). Somatic hybrid strains (G+L-X VII and V) lost the bands of $N$. langsdorffii type. On the contrary, esterase were analyzed with polyacrylamide gel electrophoresis. As seen in Fig. 4, band pattern of $\mathrm{G}+\mathrm{L}-\mathrm{X}$ VII was different from the pattern of $\mathrm{G}+\mathrm{L}$ and $\mathrm{G}+\mathrm{L}-\mathrm{X}$ IV, particularly in fast-migrating 


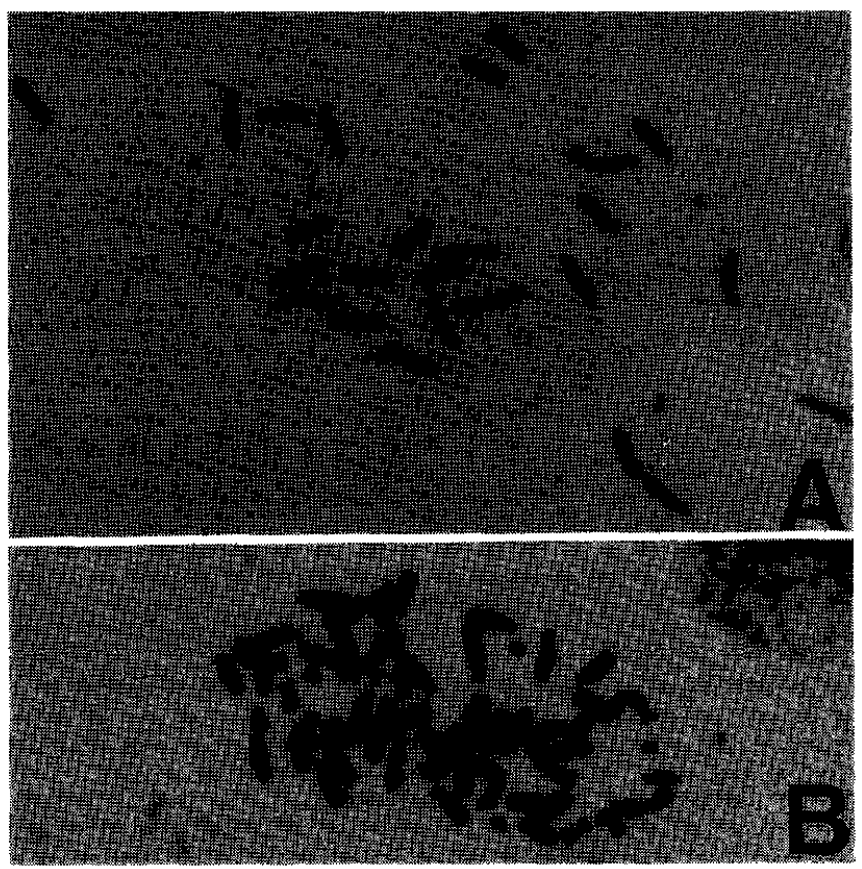

Fig. 2. Chromosomes in a cultured cell: (A) N. glauca showing 25 chromosomes, (B) a cell originated from $\mathrm{G}+\mathrm{L}-\mathrm{X}^{*}$ VII callus having chromosome fragments.

* See Table 1.

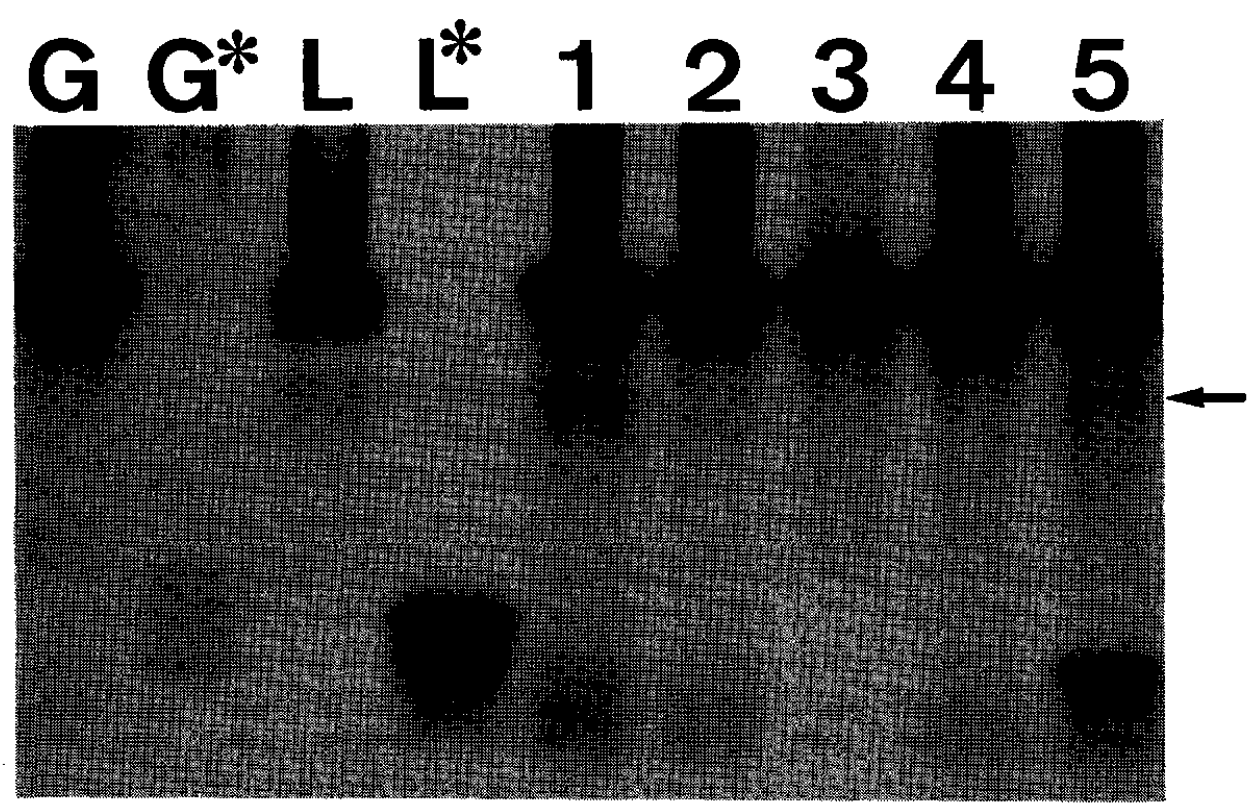

Fig. 3. Electrophoretic patterns of peroxidase extracted from leaves of $N$. glauca $\left(\mathrm{G}^{*}\right)$ and $N$. langsdorffii $\left(\mathrm{L}^{*}\right)$, and from calli of $N$. glauca $(\mathrm{G}), N$. langsdorffi $(\mathrm{L})$, $\mathrm{G}+\mathrm{L}^{* *}(1), \mathrm{G}+\mathrm{L}-\mathrm{X}^{* * *} \mathrm{IV}(2), \mathrm{VIII}(3), \mathrm{V}(4)$ and III (5). **, *** See Table 1. 


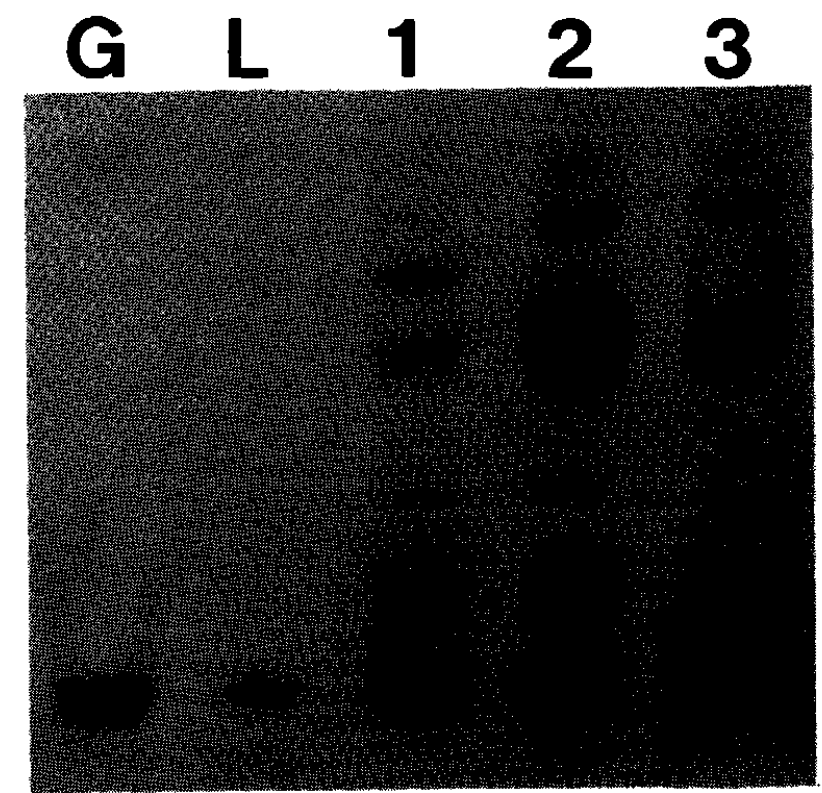

Fig. 4. Electrophoretic patterns of esterase extracted from calli of $N$. glauca ${ }_{\tilde{\xi}}(\mathrm{G})$, N. langsdorffii (L), G+L* (1), G+L-X** IV (2) and VII (3).

*, ** See Table 1.

bands. These results also indicated the elimination of $N$. langsdorffii genome by fusion with irradiated protoplasts of $N$. langsdorffii.

\section{DISCUSSION}

Cytological analysis and electrophoretic analyses of fraction 1 protein and of isozymes revealed that chromosomes of $N$. langsdorffi $i$ were eliminated to the various extent by fusion with X-ray irradiated protoplasts of $N$. langsdorffi.

Somatic hybrid calli derived from fusion with non-irradiated protoplasts had about 90 chromosomes which were much more than the sum of chromosomes of both species. A simple addition by fusion would give a hybrid with about 54-60 chromosomes. The departures from numbers of 54-60 may be attributable to several causes, e.g. multiple protoplast fusion, or unequal mitosis occuring during callus growth. During at least 6 months subculture, severe changes of chromosome numbers were not observed in somatic hybrid calli. Therefore, higher chromosome numbers may be attributable to multiple protoplast fusion. Smith et al. (1976) reported that triple fusion might have occured in the fusion between $N$. glauca and $N$. langsdorffii. If two protoplasts of $N$. glauca might have fused with one non-irradiated or irradiated protoplasts of $N$. langsdorffi in our experiment, originated calli may 
have $80-90$ or 50-67 chromosomes respectively. More detailed cytological analysis would be required in order to clarily the situation.

To accelerate the chromosome elimination from one of parents in protoplast fusion, X-ray irradiation have been utilyzed. As a result, only part of genome (or gene) have been transferred between intergeneric combinations (Dudits et al. 1980; Gupta et al. 1982). On the other hand, chromosomal recombination may have occurred in protoplast fusion between various plants (Power et al. 1975; Dudits et al. 1979, 1980; Hoffmann and Adachi 1981). Accordingly, it may be possible that by fusion with X-ray irradiated protoplasts, in synkaryons proliferating in culture, small chromosome segments are frequently into the surviving genome and thus enable genetic transfer. Furthermore, regeneration process are more sensitive to genetic constitution than mitosis is (Krumbiegel and Schieder 1981; Hoffmann and Adachi 1981). Therefore, methods of transferring only part of genome may also be useful for obtaining of somatic hybrid plants between distantly related species. Only one dose was used in our study. While effects of radiation dosage on efficiency of chloroplast transfer by protoplast fusion, that is, complete elimination of nuclei from one of parents, were investigated (Menczel et al. 1982), radiation dosage which facilitate the transfer of only part of genome (or gene) must be investigated in the future.

In intergeneric gene transfer system, albino mutant (Dudits et al. 1980) or auxotrophic mutant (Gupta et al. 1982) were utilized and also in our system, combination which express the genetic tumor was selected. However, a half selection are possible by X-ray irradiation. Furthermore, we are able to distinguish the fusion products and isolate them by a micromanipulator by selecting the combination of leaf mesophyll protoplasts and cultured protoplasts.

Valuable advice and technical help from Drs. A. Hirai and H. Uchimiya are highly appreciated.

\section{REFERENCES}

AhujA, M. R. (1968) An hypothesis and evidence concerning the genetic components controlling tumor formation in Nicotiana. Mol. Gen. Genet. 103, 176-184.

Binding, H. and NehLs, R. (1978) Somatic cell hybridization of Vicia faba + Petunia hybrida. Mol. Gen. Genet. 164, 137-143.

Blank, A., Sugiyama, R. H. and Dekker, C. A. (1982) Activity staining of nucleolitic enzymes after sodium dodecyl sulfate polyacrylamide gel electrophoresis: Use of aqueous isopropanol to remove a detergent from gels. Annal. Biochem. 120, 267-275.

Dudits, D., HadlaczkY, G. Y., Bajszar, G. Y., Koncz, C. S., LazAR, G. and Horvath, G. (1979) Plant regeneration from intergeneric cell hybrids. Plant Sci. Lett. 15, 101-112.

Dudits, D., Fejer, O., Hadlaczky, G., Koncz, C., Lazar, G. B. and Horvath, G. (1980) Intergeneric gene transfer mediated by protoplast fusion. Mol. Gen. Genet. 179, 283-288.

GLEBA, Y. Y. and HoffmanN, F. (1979) "Arabidobrassica": Plant-genome engineering by protoplast fusion. Naturwiss. 66, 547-554.

Gupta, P. P., Gupta, M. and Schigder, O. (1982) Correction of nitrate reductase defect in auxo- 
trophic plant cells through protoplast-mediated intergeneric gene transfers. Mol. Gen. Genet. 188, 378-383.

HIRAI, A. (1982) Isoelectrofocusing of non-carboxymethylated fraction 1 protein from green callus. Plant. Sci. Lett. 25, 37-41.

HoFFMANN, F. and ADACHI, T. (1981) "Arabidobrassica": Chromosomal recombination and morphogenesis in asymmetric intergeneric hybrid cells. Planta 153, 586-593.

KaHLER, A. L. and Allard, R. W. (1970) Genetics of isozyme variants in barley. I. Esterases. Crop Sci. 10, 444-448.

KAo, K. N. (1975) A chromosomal staining method for cultured cells. In Plant Tissue Culture Methods (eds. Gamborg, 0. L. and Wetter, L. R.), pp. 63-64. Prairie Regional Laboratory, Saskatoon.

KAO, K. N• (1977) Chromosome behaviour in somatic hybrids of Soybean-Nicotiana glauca. Mol. Gen. Genet. 150, 225-230.

KRUMBIEGEL, G. and SCHIEDER, O. (1981) Comparison of somatic and sexual incompatibility between Datura innoxia and Atropa belladonna. Planta 153, 466-470.

LAEMMNI, U. K. (1970) Cleavage of structural proteins during the assembly of the head of bacteriophage T4. Nature 227, 680-685.

Melchers, G., SACRistan, M. D. and HOLder, A. A. (1978) Somatic hybrid plants of potato and tomato regenerated from fused protoplasts. Carlsberg Res. Commun. 43, 203-218.

Menczel, L., Galiba, G., NAgy,F. and Maliga, P. (1982) Effect of radiation dosage on efficiency of chloroplast transfer by protoplast fusion in Nicotiana. Genetics 100, 487-495.

MOORE, G. A. and Collins, G. B. (1982) Identification of aneuploids in Nicotiana tabacum by isozyme banding patterns. Biochem. Genet. 20, 555-568.

Murashige, T. and Skoog, F. (1962) A revised medium for rapid growth and bioassays with tobacco tissue cultures. Physiol. Plant. 15, 473-497.

Power, J. B., Frearson, E. M., Hayward, C. and Cocking, E. C. (1975) Some consequences of the fusion and selective culture of Petunia and Parthenocissus protoplasts. Plant Sci. Lett. $5,197-207$.

Shepard, J. F., Bidney, D., Barsby, T. and Kemble, R. (1983) Genetic transfer in plants through interspecific protoplast fusion. Science 219, 683-688.

Sмiтh, H. H., Ka0, K. N. and CombatTI, N. C. (1976) Interspecific hybridization by protoplast fusion in Nicotiana. J. Hered. 67, 123-128.

UChimiYA, H. (1982) Somatic hybridization between male sterile Nicotiana tabacum and $N$. glutinosa through protoplast fusion. Theor. Appl. Genet. 61, 69-72.

ZELCER, A., AVIV, D. and GALUN, E. (1978) Interspecific transfer of cytoplasmic male sterility by fusion between protoplasts of normal Nicotiana sylvestris and X-ray irradiated protoplasts of male-sterile $N$. tabacum. Z. Pfanzenphysiol. 90, 397-407. 